\title{
Orçamento público: análise da formulação de estratégias sob a perspectiva do planejamento emancipatório e desenvolvimentista
}

Welles Matias de Abreu e Ricardo Corrêa Gomes

Nas últimas décadas, a gestão governamental brasileira passou por diversas mudanças, que tinham como finalidade aumentar a eficiência dos fatores de produção e da qualidade dos serviços prestados, principalmente com o incentivo à inovação e por meio da revisão de paradigmas associados aos modelos patrimonial e burocrático de administração pública. Tais mudanças resultaram em reformas gerenciais dos estados (BRESSER-Pereira, 1996), de forma a buscar maior participação e controle social (ABRUCiO E CosTA, 1998).

No processo orçamentário brasileiro, isso não foi diferente. A busca pela melhoria das funções orçamentárias (alocativa, distributiva e estabilizadora) promoveu diversas inovações nesse processo. Como exemplo, destacam-se as inovações provenientes da reforma orçamentária, implantada em 2000, que possibilitou a elaboração do programa orçamentário conforme as prioridades de governo (problemas que o governo planeja combater), com forte influência do método Planejamento Estratégico Situacional - PES (GARCIA, 2000). 
Os instrumentos de planejamento definidos como objetivos, metas, desafios e riscos, são relevantes para compor uma estratégia de desenvolvimento. Porém, é a política macroeconômica o alicerce desse processo, com as definições monetária, cambial e fiscal. Cabe ressaltar que a política fiscal foi potencializada, estrategicamente, no processo decisório de elaboração dos projetos de lei do Plano Plurianual (PPA), da Lei de Diretrizes Orçamentárias (LDO) e da Lei Orçamentária Anual (LOA), visando estabilizar a economia do país após a publicação da Lei Complementar n⿳0 101, de 4 de maio de 2000, também conhecida como Lei de Responsabilidade Fiscal (LRF).

A partir do início do presente século, a dimensão estratégica no processo orçamentário, com a influência do PES e após a edição da LRF, passa a estar mais presente na formulação das políticas públicas e, consequentemente, nas definições de prioridades governamentais, que deveriam direcionar o país para o desenvolvimento. No entanto, observa-se que as decisões macroeconômicas estão desassociadas de uma estratégia de longo prazo (SICsú, 2008). Portanto, considerando a relevância do tema, é fundamental conhecer melhor a relação entre o desenvolvimento e a gestão estratégica orçamentária - no caso do governo federal brasileiro - e suas possíveis implicações para o desenvolvimento do país.

Nesse sentido, a análise começa com o entendimento de como a administração pública brasileira, inclusive na sua dimensão estratégica, configura-se no âmbito do processo orçamentário, com vistas a responder à seguinte questão: como o orçamento público contribui para a formulação de estratégias tendo como pano de fundo a visão do planejamento emancipatório e desenvolvimentista?

Para tanto, o presente trabalho tem como objetivo geral analisar a formulação de estratégia na esfera do orçamento público, sob a perspectiva do planejamento emancipatório e desenvolvimentista, e especificamente descrever a reforma gerencial da administração pública federal, identificando quais as respectivas contribuições para o aprimoramento da gestão estratégica do orçamento público.

O presente artigo justifica-se pela importância de se proceder à análise da referida formulação, possibilitando compreender melhor como as estratégias orçamentárias podem associar-se com a visão desenvolvimentista brasileira de longo prazo. Também busca-se compreender como o neoliberalismo, que recentemente predominou como referencial de análise, não conseguiu responder à expectativa de desenvolvimento prometida, partindo da premissa de retirar o Estado da economia, estimulando a desestruturação desse e da sociedade, sem apresentar uma conjuntura econômica e desenvolvimentista bem articulada BRESSERPereira, 1996; Sicsú, 2008).

A realização deste estudo visa contribuir para uma diferente perspectiva da teoria do planejamento, considerando a recente revisão com o conceito emancipatório, em especial relacionada com a possibilidade de inferir o orçamento público como instrumento de formulação de estratégia do Estado, referente à visão desenvolvimentista. Para isso, o artigo está dividido em três partes.

Na primeira, consta o referencial teórico sobre administração pública, formulação estratégica, planejamento emancipatório, orçamento público e desenvolvimentismo. 
Em seguida, são analisadas as teorias com a finalidade de explorar as relações entre os elementos da teoria do planejamento: orçamento e estratégia, com base emancipatória. A descrição da reforma gerencial da administração pública e suas consequências para a dimensão estratégica do orçamento público. Por fim, são expostas as considerações sob a perspectiva emancipatória do orçamento público, com relação à formulação estratégica e à visão desenvolvimentista.

\section{Referencial teórico}

\section{Administração pública}

A respeito da administração pública, registra-se, inicialmente, que o Estado não é apenas um sistema constitucional legal, mas é também aparelho, organização ou administração pública (Bresser-Pereira, 2009). Sendo assim, tomando como base a Inglaterra, um dos países que primeiro se desenvolveu, apresenta-se a seguir (Quadro 1), de forma sintética, o histórico entre sociedade, Estado e administração pública.

A evolução da administração pública patrimonialista para a burocrática foi um grande progresso, conforme demonstram os estudos de Weber (KALBERG, 1980) a respeito da superioridade da burocracia sobre o modelo antecessor (patrimonialista). A primeira tem como principal característica a incapacidade ou a relutância da autoridade absolutista em separar os bens públicos dos seus bens privados, enquanto que a segunda surge com a premência de proteger os bens públicos da privatização (BRESSERPEREIRA, 1996).

No século XX, com a ampliação do papel do Estado sobre as questões sociais e econômicas, a estratégia básica adotada pela administração pública burocrática controle hierárquico e formalista ou legal sobre os procedimentos - tornou-se inadequada, pois, apesar de ser capaz de evitar a corrupção ou o nepotismo, era lenta, cara e ineficiente, fazendo sentido para um

\section{Quadro 1: Histórico das relações entre sociedade, Estado e administração pública}

\begin{tabular}{|c|c|c|}
\hline Sociedade & Estado & $\begin{array}{c}\text { Administração Pública } \\
\text { (Aparelho do Estado) }\end{array}$ \\
\hline $\begin{array}{c}\text { Aristocrática e mercantil } \\
\text { (Séculos XVI }- \text { XVIII) }\end{array}$ & Absoluto & Patrimonialista \\
\hline $\begin{array}{c}\text { Capitalista clássica } \\
\text { (Século XIX) }\end{array}$ & Liberal & Burocrática \\
\hline $\begin{array}{c}\text { Capitalista moderna } \\
\left(1^{\text {a }} \text { metade do século XX) }\right.\end{array}$ & Democrático liberal & Burocrática \\
\hline $\begin{array}{c}\text { Capitalista profissional } \\
\text { (Desde meados do século XX) }\end{array}$ & Democrático social & Gerencial \\
\hline
\end{tabular}

Fonte: Bresser-Pereira (2009, p. 17). 
Estado pequeno, mas não para um novo modelo muito mais complexo (BresserPereira, 1996).

Após a II Guerra Mundial, a influência da administração de empresas começou a se fazer sentir na administração pública, ainda que, ao mesmo tempo, houvesse uma reafirmação dos valores burocráticos. As ideias de descentralização e de flexibilização administrativa ganharam espaço em todos os governos. No entanto, a reforma da administração pública para o modelo gerencial só recebeu força a partir dos anos 1970, quando teve início a crise do Estado democrático legal de sociedade capitalista moderna, que levou a crise também à sua forma de aparelho de Estado burocrático. Em consequência, na década de 1980 iniciou-se uma grande revolução na administração pública dos países \} centrais - Inglaterra, França e Estados Unidos, entre outros desenvolvidos - em direção a uma administração pública gerencial (Osborne e GAebler, 1994). A administração pública gerencial tem como principais premissas (Bresser-PereIrA, 1996):

- descentralização do ponto de vista político, transferindo recursos e atribuições para os níveis políticos regionais e locais;

- descentralização administrativa, por meio da delegação de autoridade para os administradores públicos transformados em gerentes crescentemente autônomos;

- organizações com poucos níveis hierárquicos, ao invés de piramidal;

- pressuposto da confiança limitada e não da desconfiança total;

- controle por resultados, a posteriori, ao invés do controle rígido, passo a passo, dos processos administrativos;

- administração voltada para o atendimento do cidadão, ao invés de autorreferida.
A lógica brasileira não foi diferente: a ideia de uma administração pública gerencial é antiga, começando a ser delineada nos anos 1930 - primeira reforma administrativa -, com a criação do Departamento Administrativo do Serviço Público (Dasp), em 1936, e a introdução dos princípios centralizadores e hierárquicos da burocracia clássica. Em 1938, ocorreu o primeiro sinal de administração pública gerencial com a criação da primeira autarquia. Mas foi em 1967, com a edição do Decreto-lei n⿳丷. 200, de 25 de fevereiro de 1967 - segunda reforma -, que se tentou introduzir características gerenciais na administração pública brasileira, destacando a instituição dos princípios da descentralização e da delegação de competência. Entretanto, essa última tentativa foi parcialmente frustrada, principalmente devido ao retrocesso burocrático da Constituição Federal de 1988, provocando a necessidade de promover novo esforço para outra reforma administrativa - a terceira -, capitaneada pelo Plano Diretor da Reforma do Estado de 1995 (Bresser-Pereira, 1996; 2007).

O quadro 2, demonstra a relação entre os períodos históricos e os tipos de sociedade, Estado, regime político, classe dirigente e administração pública que ocorreram no Brasil.

A mudança do modelo burocrático de administração pública para o gerencial foi potencializada com a recente intensificação da crise do tipo de Estado democrático liberal e da sociedade capitalista moderna. O Brasil, assim como outros países, não atingiu o resultado esperado de desenvolvimento que o neoliberalismo prometeu (SICSÚ, 2008). Vive-se um vácuo histórico, que precisa ser discutido e preenchido com vistas a um estado democrático social de uma sociedade capitalista profissional e uma administração pública gerencial. 
Quadro 2: Histórico das relações entre sociedade e administração pública brasileira

\begin{tabular}{|l|c|c|c|}
\cline { 2 - 4 } \multicolumn{1}{l|}{} & $1821-1930$ & $1930-1985$ & A Partir de 1990 \\
\hline Sociedade & Patriarcal-dependente & Nacional-dependente & Nacional-dependente \\
\hline Estado & Oligárquico & Desenvolvimentista & Liberal-dependente \\
\hline Regime político & Oligárquico & $\begin{array}{c}\text { Autoritário } \\
\text { (Democrático: } 1945-1964)\end{array}$ & Democrático \\
\hline Classe dirigente & $\begin{array}{c}\text { Latifundiários e } \\
\text { Burocracia Patrimonial }\end{array}$ & $\begin{array}{c}\text { Industriais e } \\
\text { burocracia pública }\end{array}$ & $\begin{array}{c}\text { Agentes } \\
\text { financeiros e rentistas }\end{array}$ \\
\hline Administração & Patrimonial & Burocrática & Gerencial \\
\hline
\end{tabular}

Fonte: Bresser-Pereira (2007, p. 11).

\section{Formulação estratégica}

Define-se estratégia como plano, padrão, posição e perspectiva, e a formulação de estratégia como um processo de planejamento, idealizado ou apoiado por planejadores, a fim de produzir planos; ou seja, pode-se planejar (considerar seu futuro) sem se engajar em planejamento (procedimento formal), mesmo sem produzir planos (intenções explícitas). Alternativamente, existe a possibilidade de se engajar em planejamento (procedimento formalizado), apesar de não planejar (MintzBerg, 2004; 2008).

Os planejadores podem fazer tudo isso ou apenas parte, e às vezes nada disso; mesmo assim, ainda seriam úteis. Planejamento é pensar no futuro, é controlar o futuro, é a tomada de decisão integrada e um procedimento formal para produzir um resultado articulado, na forma de um sistema integrado de decisões. Planejar, por sua vez, é coordenar suas atividades, assegurar que o futuro seja levado em consideração, ser racional e controlar (KAPLAN E NORTON, 2004; MintzBerg, 2004; 2008).

Segundo Mintzberg (2000, p. 22), "para cada vantagem associada à estratégia, há uma desvantagem associada". As vantagens e desvantagens do processo de formulação de estratégias são apresentadas no quadro a seguir, remetendo-nos aos cuidados necessários durante a sua concepção.

Sicsú (2008) menciona que o Brasil precisa de um projeto de futuro para que se possa sonhar e também estabelecer vínculos entre as ações presentes e as do futuro que se deseja, rumo ao desenvolvimento pleno. Para isso, os planejadores, os planos e o planejamento são vitais e estão no contexto da formulação de estratégia, que é apresentada na figura 1.

Partindo do pressuposto de que o processo orçamentário corresponde à própria formulação de estratégia para o desenvolvimento, apresentam-se, a seguir, as teorias que colaboram com doutrinas a respeito dos seus componentes - planejadores, planos e planejamento. 


\section{Quadro 3: Vantagens e desvantagens para cada estratégia formulada}

\begin{tabular}{|c|c|c|}
\hline $\begin{array}{c}\text { Ação } \\
\text { estratégica }\end{array}$ & Vantagem & Desvantagem \\
\hline \multirow{2}{*}{ Fixar a direção } & $\begin{array}{c}\text { Mapear o curso de uma } \\
\text { organização para que ela } \\
\text { navegue coesa através do } \\
\text { seu ambiente }\end{array}$ & $\begin{array}{c}\text { Pode propiciar uma compreensão limitada } \\
\text { dos perigos em potencial, ou seja, as vezes é } \\
\text { melhor se movimentar devagar, com algum } \\
\text { cuidado, para se adaptar às novas realidades } \\
\text { que surgem a qualquer momento. }\end{array}$ \\
\hline $\begin{array}{c}\text { Focalizar o } \\
\text { esforço }\end{array}$ & $\begin{array}{c}\text { Promover a coordenação } \\
\text { das atividades }\end{array}$ & $\begin{array}{c}\text { O excesso de foco pode ofuscar a visão } \\
\text { periférica, acarretando dificuldade para abrir } \\
\text { novas possibilidades. }\end{array}$ \\
\hline organização & $\begin{array}{c}\text { Entender sua organização } \\
\text { e distingui-la das outras }\end{array}$ & $\begin{array}{c}\text { Pode ter excesso em simplificações, surgin- } \\
\text { do estereótipos, perdendo assim a rica } \\
\text { complexidade do sistema. }\end{array}$ \\
\hline $\begin{array}{c}\text { Prover } \\
\text { consistência }\end{array}$ & $\begin{array}{c}\text { Reduzir a desigualdade e } \\
\text { prover a ordem }\end{array}$ & $\begin{array}{c}\text { Perda de criatividade, uma vez que estra- } \\
\text { tégias e teorias são apenas representações } \\
\text { (abstrações) da realidade; nesse sentido, cada } \\
\text { estratégia pode ter um efeito e informação } \\
\text { falsa ou distorcida. }\end{array}$ \\
\hline
\end{tabular}

Fonte: Mintzberg (2000, p. 22).

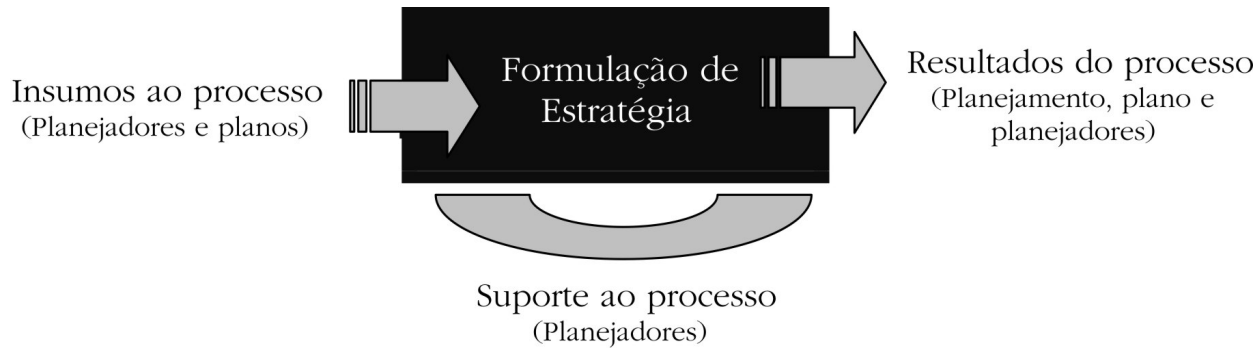

Fonte: Mintzberg (2004, p. 263)

Figura 1: Formulação de estratégia² (planejadores, planos e planejamento) 


\section{Quadro 4: Poder, conhecimento, subjetividade e espaços}

\begin{tabular}{|l|c|c|c|}
\cline { 2 - 4 } \multicolumn{1}{c|}{} & Ação comunicativa & Teoria do regime & Planejamento Emancipatório \\
\hline Poder & $\begin{array}{c}\text { Poder de rede de } \\
\text { relacionamentos, } \\
\text { capital social }\end{array}$ & $\begin{array}{c}\text { Poder preventivo, } \\
\text { sistemático de ação } \\
\text { recíproca }\end{array}$ & $\begin{array}{c}\text { Poder de rede de } \\
\text { relacionamentos }\end{array}$ \\
\hline Conhecimento & $\begin{array}{c}\text { Aprendizado } \\
\text { social }\end{array}$ & $\begin{array}{c}\text { Defesa de conhecimento } \\
\text { situacional }\end{array}$ & $\begin{array}{c}\text { Conhecimento } \\
\text { emancipatório }\end{array}$ \\
\hline Subjetividade & $\begin{array}{c}\text { Ensaiada, } \\
\text { em evolução }\end{array}$ & $\begin{array}{c}\text { Escolha racional, estratégia } \\
\text { de interesse pessoal }\end{array}$ & $\begin{array}{c}\text { Empoderamento, aplicar } \\
\text { subjetivamente, respeito } \\
\text { das diferenças }\end{array}$ \\
\hline Espaço & $\begin{array}{c}\text { Sem restrição } \\
\text { específica } \\
\text { de espaço }\end{array}$ & $\begin{array}{c}\text { Manipulação do espaço pela } \\
\text { comodidade }\end{array}$ & $\begin{array}{c}\text { Espaços de solidariedade, } \\
\text { promoção do espaço } \\
\text { de justiça }\end{array}$ \\
\hline
\end{tabular}

Fonte: Irazábal (2009, p. 129) - tradução livre

\section{Planejamento emancipatório}

Sobre os planejadores, destaca-se o estudo das interações entre as teorias do regime, da ação comunicativa e do planejamento emancipatório, como maneira de explicar as relações entre os planejadores e a governança (ver Quadro 4), utilizando as perspectivas do poder da criação de redes de relacionamentos, o conhecimento emancipatório, o empoderamento subjetivo e o espaço de solidariedade existente (IRAZÁBAL, 2009).

Especificamente quanto ao planejamento emancipatório, destacam-se as características políticas, de espécies, de processo, os objetivos e os conflitos dos planejadores para cada tipo: tradicional, democrático, equitativo e incremental, que são apresentados no Quadro 5.

\section{Orçamento público}

Com relação aos planos, segundo Sanches (2007), a Constituição de 1988 introduziu várias mudanças significativas no orçamento público, salientando a obrigatoriedade de elaboração do PPA (planejamento de médio prazo - quatro anos), e da LOA (considerada como de curto prazo - anual), com base nas metas e prioridades estabelecidas na LDO. O PPA é caracterizado pelo descompasso entre os preceitos constitucionais e as normas legais vigentes; a LOA, por ter avançado pouco nos procedimentos orientados para a alocação de recursos com a finalidade de reduzir as desigualdades interregionais; e a LDO, pela dificuldade de observar dispositivos constitucionais, a exemplo do caput do art. 204 in verbis:

Art. 204. As ações governamentais na área da assistência social serão realizadas com recursos do orçamento da seguridade social, previstos no art. 195, além de outras fontes, e organizadas com base nas seguintes diretrizes: 
Quadro 5: Características dos planejadores por tipo

\begin{tabular}{|c|c|c|c|c|}
\hline \multirow{2}{*}{ Características } & \multicolumn{4}{|c|}{ Tipos de planejadores } \\
\hline & Tradicional & Democrático & Equitativo & Incremental \\
\hline $\begin{array}{l}\text { Teoria } \\
\text { política }\end{array}$ & Tecnocracia & Democracia & Socialista & Liberal \\
\hline $\begin{array}{l}\text { Espécies de } \\
\text { planejadores }\end{array}$ & $\begin{array}{l}\text { Planejadores } \\
\text { especialistas }\end{array}$ & A sociedade & $\begin{array}{c}\text { Planejadores e } \\
\text { comunidade das } \\
\text { minorias }\end{array}$ & $\begin{array}{c}\text { Formadores de } \\
\text { políticas (vantagens } \\
\text { marginais no curto } \\
\text { prazo) }\end{array}$ \\
\hline $\begin{array}{l}\text { Tipo de } \\
\text { processo }\end{array}$ & $\begin{array}{c}\text { De cima } \\
\text { para baixo }\end{array}$ & Participativo & $\begin{array}{l}\text { De baixo para } \\
\text { cima ou represen- } \\
\text { tativo }\end{array}$ & Decisões marginais \\
\hline Objetivos & $\begin{array}{c}\text { Racional e } \\
\text { planejamento } \\
\text { científico }\end{array}$ & $\begin{array}{l}\text { O processo é mais } \\
\text { importante que os } \\
\text { resultados }\end{array}$ & $\begin{array}{l}\text { Os resultados são } \\
\text { mais importantes } \\
\text { que o processo }\end{array}$ & $\begin{array}{l}\text { Pouco planejamento } \\
\text { ou incremento por } \\
\text { mudança de políticas }\end{array}$ \\
\hline Conflitos & $\begin{array}{l}\text { Os planejadores } \\
\text { buscam resultados } \\
\text { de interesse geral } \\
\text { respaldados pelas } \\
\text { classes altas }\end{array}$ & $\begin{array}{l}\text { Dificuldade de ter } \\
\text { uma democracia } \\
\text { genuína sem a } \\
\text { representação dos } \\
\text { interesses dos gru- } \\
\text { pos de minoria }\end{array}$ & $\begin{array}{l}\text { O planejamento } \\
\text { equitativo nem } \\
\text { sempre é } \\
\text { democrático }\end{array}$ & $\begin{array}{c}\text { Os fins e os meios } \\
\text { não são formulados, } \\
\text { então os tomadores } \\
\text { de decisão podem } \\
\text { não trabalhar os } \\
\text { meios para atingir as } \\
\text { metas sociais } \\
\text { desejáveis. } \\
\text { Estratégias para } \\
\text { suportar, mas não } \\
\text { para resolver os } \\
\text { problemas. }\end{array}$ \\
\hline
\end{tabular}

Fonte: Irazábal (2009, p. 131) - tradução livre.

I- descentralização político-administrativa, cabendo a coordenação e as normas gerais à esfera federal e a coordenação e a execução dos respectivos programas às esferas estadual e municipal, bem como a entidades beneficentes e de assistência social;
II - participação da população, por meio de organizações representativas, na formulação das políticas e no controle das ações em todos os níveis.

Os citados planos têm as finalidades apresentadas no Quadro 6. 
Quadro 6: Finalidades do PPA, da LOA e da LDO

\begin{tabular}{|c|c|}
\hline Plano & Finalidade \\
\hline PPA & $\begin{array}{l}\text { Estabelecer, de forma regionalizada, as diretrizes, os objetivos e } \\
\text { metas da administração pública federal para as despesas de capital } \\
\text { e outras delas decorrentes e para as relativas aos programas de } \\
\text { natureza continuada. }\end{array}$ \\
\hline LOA & $\begin{array}{l}\text { Compreender o orçamento fiscal referente aos Poderes da União, } \\
\text { seus fundos, órgãos e entidades da administração direta e indireta, } \\
\text { inclusive fundações instituídas e mantidas pelo poder público; o } \\
\text { orçamento de investimento das empresas em que a União, direta } \\
\text { ou indiretamente, detenha a maioria do capital social com direito a } \\
\text { voto; e o orçamento da seguridade social, abrangendo todas as } \\
\text { entidades e órgãos a ela vinculados, da administração direta ou in- } \\
\text { direta, bem como os fundos e fundações instituídos e mantidos } \\
\text { pelo poder público. }\end{array}$ \\
\hline LDO & $\begin{array}{l}\text { Compreender as metas e prioridades da administração púbica } \\
\text { federal, incluindo as despesas de capital para o exercício financeiro } \\
\text { subsequente, orientar a elaboração da LOA, dispor sobre as altera- } \\
\text { ções na legislação tributária e estabelecer a política de aplicação das } \\
\text { agências financeiras oficiais de fomento. }\end{array}$ \\
\hline
\end{tabular}

Fonte: Core (2007, p. 220 - 221).

Quanto ao planejamento, este sofreu forte influência internacional - em virtude da crise financeira por volta dos anos 1980 - com vistas a, sobretudo, conferir aos governos uma administração pública enxuta, mais efetiva e eficiente, como forma de garantir mínima governabilidade e proceder a uma ampla reforma do aparelho do Estado para o modelo gerencial, em substituição ao burocrático (Core, 2004). No Brasil, a reforma orçamentária de 2000 - também denominada como terceira reforma orçamentária - teve como pontos-chave para sua implementação mudanças com fins gerenciais no processo orçamentário (GARCIA, 2000), em especial no processo de elaboração do PPA e da LOA, a saber:

- estabelecimento de objetivos estratégicos;

- identificação de problemas a enfrentar ou de oportunidades a aproveitar, para alcançar os objetivos estratégicos;

- concepção de programas a serem implementados, com vistas ao atingimento dos objetivos, que implicarão a solução dos problemas; 
- especificação das diferentes ações do programa, com identificação dos produtos que darão origem, quando couber, aos projetos e atividades;

- atribuição de indicadores aos objetivos (e programas) e de metas aos produtos (projetos, atividades e outras ações);

- designação de gerentes por programas;

- avaliação da execução e dos resultados; e

- cobrança e prestação de contas por desempenho.

\section{Desenvolvimentismo}

As promoções do desenvolvimento e da democracia social no Brasil interessam não apenas ao governo nacional, mas também às elites econômicas e empresariais mundiais, coadjuvantes e beneficiárias dos processos de desenvolvimento econômico e de democratização. Políticas atualmente prescritas por essas instituições aos países em desenvolvimento como boas - com características neoliberais - contrariam as lições do passado, impedindo esses países de "subirem a escada" em direção ao mundo desenvolvido. Uma colaboração para resolver esse dilema é saber como construir uma "escada" (estratégia), ou seja, como definir quais são os passos ou caminhos a serem adotados para que se possa alcançar o desenvolvimento.

É necessário que se conheça os meios utilizados por outros países para atingir seus objetivos estratégicos, de modo a vislumbrar uma alternativa possível. Desse modo, o país conseguirá superar obstáculos impostos pelas instituições internacionais, bem como as condições históricas diversas e a conjuntura política e institucional. Cabe lembrar que muitas das alternativas adotadas no passado pelos países que hoje são considerados como desenvolvidos não estão mais disponíveis para os países em desenvolvimento (Olivieri, 2005).

Rumo ao desenvolvimento social, é fundamental saber que qualquer estratégia orçamentária escolhida tem inevitáveis consequências econômicas e sociais, esperadas ou não, que devem estar em um contexto de análise de vulnerabilidade e confiabilidade do plano, de forma a aumentar a capacidade de governo. Segundo Sicsú (2009), para desenvolver-se, o Estado deve prover uma política fiscal que estimule o aumento da receita tributária como consequência da sua atuação, utilizando o critério da progressividade. Deve executar obras de infraestrutura para a promoção do desenvolvimento industrial e, consequentemente, produção de bens e serviços sociais, capaz de gerar empregos e redistribuição da renda nacional.

Nesse sentido, o desenvolvimento deve ser proveniente do incremento imediato em despesas geradoras de emprego e em áreas sociais - e discriminado - que promova a distribuição de renda - dos gastos na ampliação da capacidade produtiva, o qual exige estímulos não só fiscais, mas também monetários e cambiais, compondo uma proposta de política macroeconômica desenvolvimentista (Gentil e Michel, 2009).

De forma semelhante, BresserPereira e Nakano (2002) afirmam que a estabilidade macroeconômica é compatível com o desenvolvimento econômico desde que com a adoção de uma política monetária de juros favorável à ativação das políticas comerciais e industriais (geradoras de emprego), de política cambial realista (flutuante) para estabilizar nossas contas externas e de política fiscal que possibilite a distribuição por meio do aporte de recursos em políticas públicas sociais (a exemplo da educação básica, saúde e 
reforma agrária), além de ter o critério da progressividade da tributação.

Sicsú (2008) expõe que essas estratégias só são efetivas se houver envolvimento de toda a sociedade. Portanto, a formulação da estratégia orçamentária para o desenvolvimento não pode ser um plano de gabinete, mas sim um processo de construção conjunta com a sociedade, um sonho da grande maioria da população, com ampla participação política do Estado-Nação Brasil.

\section{Análise teórica}

Apesar de a reforma orçamentária de 2000 representar um marco histórico com destaque para os esforços das secretarias de Planejamento e Investimentos Estratégicos (SPI, na denominação atual) e de Orçamento Federal (SOF), ambas subordinadas ao Ministério do Planejamento, Orçamento e Gestão, ainda há um longo caminho para a implantação de um sistema de planejamento pleno e apropriado à complexidade do processo de governar em sociedades democráticas, que supere o "economicismo", incorpore cálculo político e disponha de direção estratégica. Todavia, admite-se que a prática orçamentária atual é bem superior ao que se praticava até então. Considerando que a reorganização do sistema está em andamento, esse fato aponta para o rumo do que vem a ser buscado pelos países com governos mais bem organizados e mais capacitados à condução estratégica dos negócios públicos (GARCIA, 2000).

A construção de um poderoso instrumento de governo, que utilize o sistema de planejamento estratégico público, requer, antes de tudo, consciência de sua necessidade. Segundo Garcia (2000, p. 39), "não há indícios seguros de que essa consciência esteja generalizada entre dirigentes públicos, parlamentares, quadros técnicos superiores, universidades, partidos políticos". Um exemplo é o atraso da edição de lei complementar de que trata o $\int 9^{\circ}$ do art. 165 da Constituição Federal, podendo ser conclusão de nosso próprio atraso político-institucional (SANCHES, 2007). Ressalta-se a importância dos planejadores para a efetivação das mudanças evolutivas.

Em 2000, com a publicação da LRF, a austeridade fiscal contribui para o processo de reforma gerencial do Estado, com a instituição de mecanismos de controle fiscal - fortemente vinculados à LOA e à LDO - para todas as esferas (federal, estadual e municipal), que juntamente com os esforços para a integração entre os planos PPA e LOA, buscaram influenciar o Estado, estrategicamente, para a elevação de produtividade e qualidade de seus serviços. Contudo, o planejamento, num ambiente de forte disciplina fiscal, ocupa espaço considerável, tendendo a ter excessivamente perfil incremental, que poderia ser do PPA, uma vez que valorizaria as relações entre a gestão fiscal e o gasto público sob a ótica estratégica de médio e longo prazo (Pares e VAlle, 2007).

Independente do formato do plano, percebe-se a necessidade de se associar técnicas de gestão estratégica na administração pública ao planejamento estratégico. Nesse contexto, o Planejamento Estratégico Situacional (PES) colaborou para influenciar a reforma orçamentária de 2000, aumentando a dimensão estratégica no processo orçamentário (PARES E VALLE, 2007). Para Matus (1997), no PES o momento fundamental para o processo de planejamento significa "instância, ocasião, circunstância ou conjuntura pela qual passa um processo contínuo, ou em cadeia, que não tem começo nem fim definidos" e pode ser tipificado, sem sequência 
predefinida, como explicativo (foi, é, tende a ser), normativo (deve ser), estratégico (pode ser) e tático-operacional (fazer). Se essas condições fossem atendidas plenamente, fariam com que o planejamento tivesse características menos tradicionais.

De acordo com Matus (2007), a urgência que nos leva à preocupação com o curto prazo nos distrai da planificação do longo prazo. Sendo assim, a grande estratégia é pensar grande as estratégias (visão ampla), para evitar a cegueira do curto prazo (visão curta).

Pode-se visualizar na Figura 2, de forma sintética, as propostas do PES, cujo fundamento é a teoria de um jogo semicontrolado a serviço da prática racional da ação humana, contendo a relação denominada "triângulo de governo", composto por "governabilidade, capacidade e projeto de governo".

A atual administração pública brasileira passa a ser, a partir de 1990, classificada predominantemente como gerencial, influenciada pela tendência internacional de incluir características de administração de empresas na administração pública, como na questão colocada por Osborne e Gaebler (1994, p. 21): "por que não se pode governar como quem administra uma empresa?". O perfil empreendedor passa a ser cobrado para o administrador público com a finalidade de o governo produzir mais e com melhor qualidade, utilizando menos recursos. São premissas para esse novo perfil, que estão presentes no Plano Diretor da Reforma do Estado de 1995. Como acreditar no governo, nas possibilidades geradas pela equidade - igualdade de oportunidades para todos os cidadãos -, no funcionamento efetivo da sociedade sem um governo efetivo e que o liberalismo e o conservadorismo tradicional não têm muita relevância para os problemas atuais.

O orçamento público federal brasileiro seguiu a referida tendência. A reforma orçamentária de 2000 introduziu mudanças com características gerenciais no processo orçamentário que, entre outros

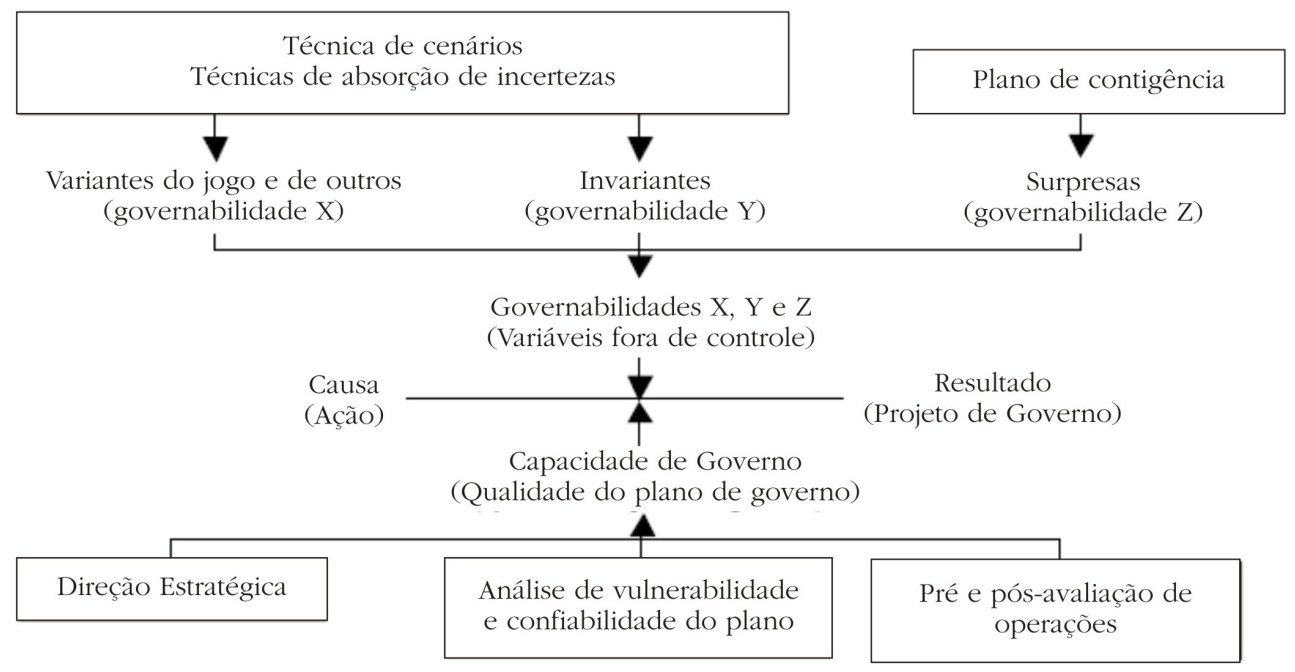

Fonte: Matus (2007, p. 115 - 131).

Figura 2: Planejamento Estratégico Situacional - PES 
objetivos, buscaram aumentar a sua dimensão estratégica, principalmente com a influência do método PES, para todos os componentes de sua formulação planejadores, planos e planejamento. Mesmo sabendo que o processo ainda está longe do ideal, com certeza representou um grande avanço na técnica orçamentária, pelo fato de possibilitar a vinculação da estratégia com o planejamento em situações complexas como vivenciam os atuais governos.

A baixa efetividade estratégica (macroeconômica, orçamentária e de políticas públicas) para a promoção do desenvolvimento pode ser explicada pelos seguintes fatores: o pouco tempo da implantação das mudanças propostas no processo orçamentário e a apatia de uma administração pública burocrática, presente em um Estado democrático liberal estagnado.

Nesse sentido, para se desenvolver, tornar-se uma democracia social, é importante que o planejamento evolua com os planos - observando o planejamento emancipatório - para obter características equitativas e democráticas, conforme figura a seguir, com as interações para promoção do desenvolvimento do país.

Para o Estado se consolidar como desenvolvido, a estratégia orçamentária deve considerar a perspectiva social. Os desenvolvimentistas consideram que a tributação tem de ser progressiva e justa; que os juros devem ser baixos e menos custosos; que precisa haver investimentos privados e câmbio que estimule a exportação; além da geração de empregos por intermédio de investimentos públicos em infraestrutura e políticas sociais de longo prazo, como forma de estimular a produção e distribuição de renda. Nesse contexto, os planejadores têm papel fundamental para a realização dessas ações, uma vez que o processo emancipatório está relacionado com o comportamento do componente (planejadores) da formulação de estratégia.

\section{Considerações finais}

Para que a formulação da estratégia orçamentária seja efetiva, com base na teoria de Mintzberg (2000), observa-se a necessidade de:

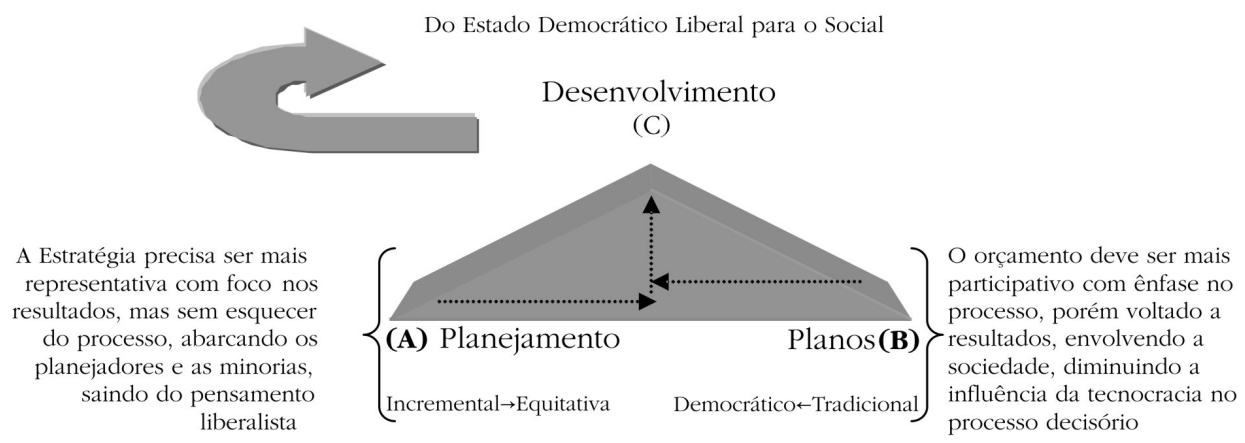

Fonte: Autores.

Figura 3: Interações entre planejamento e planos para o desenvolvimento 
- fixação da direção sem ocultar perigos em potencial, ou seja, estar aberta a adaptar-se às novas realidades;

- focalização dos esforços preocupando-se em não ofuscar a visão periférica, considerando, portanto, novas possibilidades;

- definição da organização observando as complexidades, porém evitando excessos de padronizações; e

- prevenção da consistência - igualdade e ordem - com criatividade.

A gestão estratégica contribui para o desenvolvimento, garantindo a estabilidade econômica mediante políticas fiscal, monetária e cambial, além da condição responsável pelo incremento de receitas e despesas públicas, gerando empregos por meio da implantação de infraestrutura que estimule a produção agropecuária, industrial e de serviços, e distribuindo renda por intermédio de tributação progressiva e priorização de políticas públicas sociais.
Para isso, a estratégia e o orçamento público se aproximam, com o propósito de estimular o processo participativo, de construção conjunta do governo com a sociedade, representativo de fato e com ampla participação política. Essa aproximação se dirige à forma de administração pública gerencial, orientada para resultados sem desconsiderar a importância dos processos, flexível para as situações complexas não previsíveis, como preconiza o método PES, e justa para conduzir o Estado ao tipo democrático social. Entretanto, para ser eficaz, esta estratégia necessita prever que os planejadores busquem um modelo de gestão mais equitativo e democrático (Quadro 7), deixando de ser excessivamente tradicional e incremental.

O desenvolvimento orçamentário brasileiro depende, consideravelmente, da ruptura do imediatismo incremental liberalista (buscar uma visão ampla) e da diminuição da influência da elite nas

\section{Quadro 7: Planejador desenvolvimentista (equitativo e democrático)}

\begin{tabular}{|c|c|}
\hline Planejamento emancipatório & $\begin{array}{c}\text { Planejadores desenvolvimentistas com } \\
\text { foco no perfil equitativo } \\
\text { e democrático }\end{array}$ \\
\hline Poder de rede de relacionamentos & $\begin{array}{c}\text { Com mobilização da sociedade, dos } \\
\text { planejadores e da comunidade das } \\
\text { minorias }\end{array}$ \\
\hline Conhecimento emancipatório & $\begin{array}{c}\text { Provimento do saber considerando } \\
\text { processo participativo e representativo } \\
\text { autogerido }\end{array}$ \\
\hline $\begin{array}{c}\text { Empoderamento, aplicar } \\
\text { subjetivamente, respeito às diferenças }\end{array}$ & $\begin{array}{c}\text { Consideração da relevância entre o } \\
\text { processo e os resultados para a } \\
\text { coletividade }\end{array}$ \\
\hline $\begin{array}{c}\text { Espaços de solidariedade e promoção } \\
\text { do espaço de justiça }\end{array}$ & $\begin{array}{c}\text { Busca pela democracia social com } \\
\text { equidade }\end{array}$ \\
\hline
\end{tabular}

Fonte: Autores. 
decisões estratégicas (realizar concessões às minorias), de maneira a permitir a construção de um novo paradigma, em que a sociedade esteja mais presente na formação da estratégia macroeconômica (planejadores, planos e planejamento) e do processo decisório das políticas públicas relacionado ao orçamento público brasileiro, com perfil representativo, participativo e mobilizador.

As ideias provenientes dos debates da reforma orçamentária de 2000, com base nas orientações contidas no Plano Diretor da Reforma do Aparelho Estado de 1995, ainda estão em processo de implementação e precisam ser constantemente reforçadas ou revistas, tendo em vista as novas conjunturas políticas e econômicas. Para tanto, os planejadores são os agentes eman-cipatórios da formulação de estratégia com características mais equitativas e democráticas, visto serem eles os responsáveis pelas ações desenvolvimentistas nos planos e no planejamento. $\mathrm{O}$ intuito é de que as propostas deixem de ser tradicionais e incrementais, conforme se observa nas decisões do atual processo orçamentário brasileiro.

(Artigo recebido em janeiro de 2010. Versão final em setembro de 2010.)

\section{Notas}

1 Periodização e tipologia tomando como base a Inglaterra.

2 Escola do Design.

\section{Referências bibliográficas}

Abrucio, F. L. e V. M. F. Costa. Reforma do Estado e o Contexto Federativo Brasileiro. Pesquisas, 1998, v. 12, p. 1 - 187.

Bresser-Pereira, L. C. Da Administração Pública Burocrática à Gerencial. Revista do Serviço Público, v. 47, jan./abr. 1996.

Burocracia Pública e Classes Dirigentes no Brasil. Revista de Sociologia e Politica, 2007, v. 28, p. 9 - 30.

Nação, Sociedade Civil, Estado e Estado-Nação: Uma Perspectiva Histórica. Textos para Discussão, v. 189, jun. 2009.

Bresser-Pereira, L. C. e Y. Nakano. Uma Estratégia de Desenvolvimento com Estabilidade. Revista de Economia e Política, v. 22, p.146 - 180, jul. a set. de 2002.

Core, F. G. Reformas Orçamentárias no Brasil: Uma Trajetória de Tradição e Formalismo na Alocação dos Recursos Públicos. IX Congreso Internacional Del Clad sobre La Reforma Del Estado y De La Administración Pública. Madrid, España: Clad, 2004.

Reforma Gerencial dos Processos de Planejamento e Orçamento. In: Giacomoni J.; Pagnussat J. L. (Ed.). Planejamento e Orçamento Governamental, ENAP, 2007, v. 2 p. $219-261$. 
Garcia, R. C. A Reorganização do Processo de Planejamento do Governo Federal: O PPA 2000-2003. Texto para Discussão, n. 726, IPEA, Brasília, mai. de 2000.

Gentil, D. L. e R. Michel. Estratégia de Desenvolvimento e Intervenção Fiscal do Estado. In: Sicsú, J.; Castelar, A. Sociedade e Economia: Estratégias de Crescimento e Desenvolvimento. Brasília: IPEA, 2009. p.131 - 142.

IrAZÁBAL, C. Realizing Planning's Emancipatory Promise: Learning From regime Theory to Strengthen Communicative Action. Planning Theory, 2009, v. 8, p. 115 -139.

Kalberg, S. Max Weber's Types of Rationality: Cornerstones for the Analysis of Rationalization Processes in History. The American Journal of Sociology, Chicago, The Chicago University Press, v. 85, n. 5, p. 1145 - 1179; mar. de 1980.

Kaplan, R. S. e D. P. Norton. Mapas Estratégicos: Convertendo Ativos Intangíveis em Resultados Tangíveis. Rio de Janeiro: Elsevier, 2004.

Matus, C. Política, Planejamento e Governo. Brasília: IPEA, 1997.

. O Plano como Aposta. In: Giacomoni, J.; Pagnussat, J. L. Planejamento e Orçamento Governamental. 2007, v. 1, p. 115 - 144.

Mintzberg, H. Safari de Estratégia. Porto Alegre: Bookman, 2000. - Ascensão e Queda do Planejamento Estratégico. Porto Alegre: Bookman, 2004.

. Criando Organizações Eficazes (Estruturas em Cinco Configurações). São Paulo: Atlas, 2008.

Olivieri, C. Como Construir uma Estratégia de Desenvolvimento? Resenha 1 do texto Chutando a Escada: A Estratégia do Desenvolvimento em Perspectiva Histórica de Ha-Joon Chang. RAE Eletrônica. São Paulo: Unesp, 2005.

Osborne, D. Reinventando o Governo. Brasília: Ed. MH Comunicação, 1994.

Pares, A.; Valle, B. A Retomada do Planejamento Governamental no Brasil e seus Desafios. In: Giacomoni, J.; Pagnussat, J. L. Planejamento e Orçamento Governamental, 2007, v.1, p. 229 - 270.

SAnches, O. M. O Ciclo Orçamentário: Uma Reavaliação à Luz da Constituição de 1988. In: Giacomoni, J.; Pagnussat, J. L. Planejamento e Orçamento Governamental. Brasília: ENAP, 2007, v. 2, p.187 - 217.

Sicsú, J. Planejamento Estratégico do Desenvolvimento e as Políticas Macroeconômicas. Texto para Discussão, n. 1346, IPEA, Brasília, ago. de 2008.

. A Construção de uma Estratégia de Desenvolvimento. In: Sicsú, J.; Castelar. A.

Sociedade e Economia: Estratégias de Crescimento e Desenvolvimento. Brasilia: IPEA. p.19-28, 2009. 


\section{Resumo-Resumen-Abstract}

Orçamento público: análise da formulação de estratégias sob a perspectiva do planejamento emancipatório e desenvolvimentista.

Welles Matias de Abren e Ricardo Corrêa Gomes

Este artigo tem como finalidade analisar a formulação de estratégia no orçamento público sob a perspectiva do planejamento emancipatório e desenvolvimentista. Além disso, busca-se descrever a reforma gerencial da administração pública federal e identificar quais as respectivas contribuições para o aprimoramento da gestão estratégica do orçamento público. Apresenta-se como referencial a teoria do planejamento, abordando temas relacionados com administração pública, formulação estratégica, planejamento emancipatório, orçamento público e desenvolvimentismo. A análise da teoria foca as relações entre os elementos do planejamento: orçamento e estratégia, com base emancipatória. Descreve-se a reforma gerencial da administração pública e suas consequências para a gestão estratégica orçamentária. Emite-se considerações sob a perspectiva emancipatória do orçamento público, com relação à formulação estratégica e à visão desenvolvimentista.

Palavras-chaves: Orçamento Público - Formulação de estratégia - Desenvolvimentismo emancipatório.

\section{Presupuesto público: análisis de la formulación de estrategias bajo la perspectiva del planeamiento emancipatório y desarrollista. \\ Welles Matias de Abreu y Ricardo Corrêa Gomes}

Este artículo tiene como propósito analizar la formulación de la estrategia en el alcance del presupuesto público bajo perspectiva del planeamiento emancipatorio y desarrollista. Por otra parte, se busca describir la reforma gerencial de la administración pública federal y identificar cuáles son las respectivas contribuciones para la mejora de la gerencia estratégica del presupuesto público. La teoría del planeamiento se presenta como el tema referencial, abordando temas relacionados con la administración pública, la formulación estratégica, el planeamiento emancipatorio, el presupuesto público y desarrollista. El análisis de las teorías enfoca las relaciones entre los elementos del planeamiento: presupuesto y estrategia, con la base emancipatoria. Se describe la reforma gerencial de la administración pública y sus consecuencias para la gerencia estratégica presupuestaria. Se emite consideraciones bajo perspectiva emancipatoria del presupuesto público, con respecto a la formulación estratégica y a la visión desarrollista.

Palabras-claves: Presupuesto público - Formulación estratégica - Desarrollismo emancipatorio.

Public budget: analysis of the strategies' formulation under the perspective of the emancipatory and developmentist planning.

Welles Matias de Abreu and Ricardo Corrêa Gomes

This article is aimed to analyse the formulation of strategies in the scope of public budget under the emancipatory and developmental planning perspective. Besides, it tries to describe the management reform of the federal public administration and to identify which are the respective contributions for the improvement of the strategic management of the public budget. It presents as reference the planning theory, broaching related subjects with public administration, strategic formulation, emancipatory planning, public budget and development. The analysis of the theory focuses the relations between the planning elements: budget and strategy, with emancipatory basis. It describes the management reform of the public administration and its consequences for the 
budgetary strategic management. It emit considerations under the emancipatory perspective of the public budget, with regards to the strategic formulation and to the developmental view.

Keywords: public budget - strategy formulation - developmentist emancipator.

Welles Matias de Abreu

Pós-Graduado em Planejamento e Orçamento pela Fundação Getúlio Vargas (FGV-Brasília) e em Gestão Pública pela Escola Nacional de Administração Pública (ENAP). Mestrando em Administração pela Universidade de Brasília (UnB). É servidor da carreira de Analista de Planejamento e Orçamento do governo federal, ocupando atualmente o cargo de coordenador-geral de Desenvolvimento Institucional da Secretaria de Orçamento Federal. Contato: welles@unb.br

Ricardo Corrêa Gomes

Doutor em Administração Pública pela Universidade de Aston no Reino Unido. É Professor Adjunto da UnB, vice-presidente para a América do Sul e Central da International Research Society for Public Management (IRSPM) e representante da América do Sul no Conselho Editorial da revista científica International Journal of Public Sector Management (IJPSM). Contato: rgomes@unb.br 